\title{
Invasive species watch lists: guidance for development, communication, and application
}

\author{
Jamie K. Reaser (1D) Mark Frey • N. Marshall Meyers
}

Received: 3 November 2019/Accepted: 3 November 2019/Published online: 31 December 2019

(C) The Author(s) 2019

\begin{abstract}
A watch list is a list of invasive species to be prioritized for surveillance, reporting, and other possible responses in order to reduce the risk of impact to valued assets. Watch lists are basic, yet multifunctional tools for the early detection of and rapid response to invasive species. There is, however, a need to substantially improve watch list standardization, accessibility, and associated communication strategies. We provide guidance to achieve these aims, including an overview of guiding principles and a list of questions to consider when one develops, communicates, and applies invasive species watch lists. Our guidance is intended to support invasive species watch lists development and application globally.
\end{abstract}

Keywords Invasive species - Watch list - Detection Survey - Early detection and rapid response (EDRR) . Guidance

J. K. Reaser $(\bowtie)$

Center for Large Landscape Conservation, $303 \mathrm{~W}$

Mendenhall St \#4, Bozeman, MT 59715, USA

e-mail: jamiekreaser@gmail.com

M. Frey

National Park Service, 100 Alabama St., SW, Atlanta,

GA 30306, USA

N. M. Meyers

PLLC, 1620 L Street, NW, Ste 610, Washington,

DC 20036, USA

\section{Introduction}

An invasive species is, "with regard to a particular ecosystem, a non-native organism whose introduction causes or is likely to cause economic or environmental harm, or harm to human, animal, or plant health" (Executive Office of the President 2016). The 20162018 National Invasive Species Council (NISC) Management Plan (NISC 2016) calls for an assessment of the US government's capacity to produce invasive species watch lists. For the purposes of this paper, we define a watch list as a list of invasive species to be prioritized for surveillance (pre-discovery), reporting, monitoring (post-discovery), and other possible response measures in order to reduce the risk of impact to valued assets. Herein, we provide guidance for the standardized development, communication, and application of watch lists with a view towards supporting a national program for the early detection of and rapid response to invasive species (EDRR). Although this guidance is provided in the context of a US government directive, the manuscript is applicable to invasive species watch lists worldwide.

In the context of EDRR, it is important to clarify the relationship between a watch list and a checklist. Typically, a checklist is a list of species that have been documented (observed and identified) within a specific area. It reflects knowledge of species occurrence. By comparison, species included on a watch list may or may not have already been detected and identified 
within a specific area. A watch list is intended to guide surveillance and reporting by including species that pose a risk of introduction as well as those thought to already be introduced, but not yet reported; consequently, watch lists do not necessarily reflect species occurrence.

Checklists can, however, be vital tools for creating watch lists. For example, a state may reference a neighboring state's checklist in order to determine what invasive species have been detected there that they wish to keep from spreading and establishing in their own state. Likewise, a country may review a trading partner's national invasive species checklist (or their species occurrence data more generally) in order to develop a ports of entry watch list. At the national scale, the US Geological Survey's Biodiversity Information Serving Our Nation (BISON; https:// bison.usgs.gov, accessed 19 September 2019) information system is being enhanced to provide non-native species occurrence data and analytical tools (Reaser et al. 2019a, this issue). At the global scale, the Global Register of Introduced and Invasive Species (GRIIS; http://www.griis.org, accessed 19 September 2019) and associated products of the IUCN Invasive Species Specialist Group, Global Biodiversity Information Facility (GBIF; https://www.gbif.org, accessed 19 September 2019), and CABI Invasive Species Compendium (https://www.cabi.org/isc, accessed 19 September 2019) are particularly useful resources.

A survey and supporting assessments conducted to inform responses to the aforementioned NISC Management Plan directive (Reaser et al. 2019b, this issue) revealed that some federal agencies are routinely employing watch lists while others use them on an ad hoc basis. In general, watch list development, communication, and application has not been standardized within or among agencies and issues may arise regarding the authoritative nature and timeliness of watch lists. The following guidance is intended to advance the capacity of government agencies and their partners to effectively employ watch lists, particularly in the EDRR context.

\section{General principles}

Watch lists are products of and tools applied within a systematic approach to EDRR preparedness and operation (Reaser et al. 2019a, this issue). Watch lists may be necessitated by various laws and policies in order to meet regulatory priorities in an effective and cost-efficient manner (Burgos-Rodríguez and Burgiel 2019, this issue). Watch list development and updating must be driven by the best available science. Watch lists need to be backed by the accurate identification of species and accurately communicate the characteristics for species identification (Lyal and Miller 2019, this issue). Although organizations have used expert opinion to develop watch lists at a range of scales, risk evaluation is necessary to produce scientifically informed and legally defensible watch lists (Meyers et al. 2019, this issue). Watch lists are also valuable tools for informing the target analyses intended to increase the likelihood of invasive species detection (Morisette et al. 2019, this issue).

Watch lists provide guidance for prioritizing invasive species surveillance and reporting in a particular area defined in ecological and/or jurisdictional terms. Agencies responsible for inspecting cargo and equipment as they enter a country may produce watch lists for specific ports of entry (e.g., Animal and Plant Health Inspection Service 2012; https://pestlens.info, accessed 31 August 2018). Frey (2017) developed a watch list for plants in US national parks spread across a region of less than $25,000 \mathrm{~km}^{2}$. Drucker et al. (2008) provide a case study for watch list development in Colorado. The Environmental Law Institute (2004) has provided guidance for creating invasive species watch lists for the Great Lakes states. Faulkner et al. (2014) describe a watch list system for South Africa. Because biological invasion is a dynamic process, watch lists are spatially and temporally limited and, as a standard operating procedure, need to be updated accordingly. The value of having a particular species on a watch list will change with time in keeping with changes in the risk posed by the species. If the species is verifiably eradicated from an invasion pathway or neighboring area, continuing to prioritize monitoring and surveillance may be a poor use of limited resources. The return on investment for surveillance may also drop considerably if the species bypasses prevention measures and becomes well established in a given area.

Although all watch lists serve as tools for guiding surveillance and reporting priorities, there are a wide range of goals for invasive species surveillance and reporting. These non-exclusive goals may include preventing the introduction of invasive species 
(especially regulated species; Burgos-Rodríguez and Burgiel 2019, this issue), limiting the spread of already established invasive species, collecting data for scientific research to better understand the biology and distribution of the species, monitoring for species after response measures have been taken in order to ascertain effectiveness and/or detect reinvading organisms, training surveillance personnel (professional staff and/or citizen scientists), and raising public awareness of and engagement in the invasive species issue. Reducing impact risk is frequently an overarching goal for addressing invasive species. In the context of watch list development, the risks in question must be clearly defined: risk to what, where, and when.

The criteria for placing invasive species on a watch list vary according to the goals. Three of the most important criteria to consider are (a) the regulatory foundation for detection and response measures, (b) the level of scientific rigor necessary to inform the watch list in accordance with risk evaluation (which may be established in law and/or policy), and (c) the feasibility for response to detected species (beyond regulation). If there is a low feasibility for response, then there will be little motivation for surveillance and reporting. Watch list developers must also consider the geographic area and species diversity that need to be addressed to meet project goals; the number of taxa and area of coverage influence practicality and the willingness of people to engage in surveillance and reporting. If potential surveyors feel intimidated or overwhelmed by expectations, the watch list may decrease rather than increase overall detection and reporting capacity.

The series of actions to be taken once a species on a watch list has been detected will also vary according to the goals. The roles and responsibilities need to be apparent to the potential detectors and supported by relevant authorities and clearly defined communication strategies. For example, Burgiel (2019, this issue) addresses Incident Command Systems in the EDRR context in a complementary guidance paper.

As standalone tools, watch lists are unlikely to be effective. Ideally, watch lists are employed as part of a programmatic communication strategy that takes social marketing principles into consideration. In the EDRR context, watch lists are needed to help (1) enlist as many well-informed people in surveillance as possible and (2) increase the likelihood that target species are rapidly and accurately reported to the appropriate authorities. Success, therefore, depends on an understanding of what will maximize the motivation and technical capacities of the watch list user (i.e., the target audience). If there are multiple target audiences, multiple approaches to watch list execution may be necessary.

When watch lists are used as part of a regulatory framework that has implications for trade and/or land management practices, it is imperative that the process for developing watch lists is science-based, standardized, up-to-date, and transparent to the public. It is advisable to include information on whom to contact if concerns arise over watch list accuracy, what actions the individual detecting a species is requested to take, and what laws are relevant in the detection and response context.

\section{Watch list considerations}

The following is a list of questions to consider when developing, communicating, and applying invasive species watch lists. These questions are intended to help identify the criteria that need to be met to ensure that watch lists are as effective as possible, particularly when employed as an EDRR tool.

(1) What is the goal(s) for the watch list?

(2) What is the regulatory or policy framework(s) (if any) that supports this goal(s)? What agency authority and specific parameters does it convey that are applicable to watch lists?

(3) What geographic/jurisdictional area is to be covered by the watch list?

(4) What scientific information and tools are available to inform watch list development? How will they be applied initially and used to inform watch list updates?

(5) What standard process is used to determine what goes on the watch list, and how will this process be transparently communicated to the public?

(6) Who is the target audience(s) for the watch list and what actions are they expected to take?

(7) How will the target audience know about and obtain the watch list? 
(8) What skill sets does the target audience have for species identification? What resources are available to assist with species identification?

(9) What format(s) (e.g., poster, brochure, smartphone app) will be most effective in communicating the watch list to the target audience?

(10) What motivates the target audience to conduct surveillance and reporting? What will keep the target audience motivated if the chances of encountering the target organism(s) are rare?

(11) How will the target audience know what to do once they detect a target organism?

(12) How long is the watch list good for, who is responsible for updating, and what is the process for updating and communicating those updates?

(13) What are the implications for errors or out of date information on the watch lists, and who is accountable?

A catalog of invasive species lists at various geographic scales is available through the National Agricultural Library (https://www. invasivespeciesinfo.gov/resources/lists.shtml, accessed 19 September 2019). Each of these examples can be evaluated according to the above criteria in order to test the likelihood of effectiveness in specific contexts.

\section{Conclusion}

Watch lists are basic, yet multi-functional tools for invasive species EDRR. There is, however, a need to substantially improve watch list standardization, accessibility, and associated communication strategies. Undoubtedly, increases in computing power and application, as well as advancements in other EDRR support tools (especially risk screening), will lead to growing demands for watch list use and quality. The guidance offered herein is not intended to be prescriptive or comprehensive, rather it provides a general reference point for developing and employing invasive species watch lists, particularly when the goal is to detect and respond to invasive species as rapidly and effectively as possible.

Acknowledgements This document advances action 5.1.3 of the 2016-2018 NISC Management Plan. The authors are grateful to everyone who contributed to the federal agency surveys and supplemental inquires. The authors thank Gerald "Stinger" Guala, Carrie Seltzer, Jason Kirkey, Sarah Veatch, Laura Meyerson, and Dan Simberloff for reviews that improved the manuscript. Financial support for this project was provided through Service First funding to the NISC Secretariat. The views expressed in this publication are solely those of the authors and do not necessarily reflect the views of the United States Government. The majority of Jamie K. Reaser's contributions occurred while Executive Director of the National Invasive Species Council.

Open Access This article is licensed under a Creative Commons Attribution 4.0 International License, which permits use, sharing, adaptation, distribution and reproduction in any medium or format, as long as you give appropriate credit to the original author(s) and the source, provide a link to the Creative Commons licence, and indicate if changes were made. The images or other third party material in this article are included in the article's Creative Commons licence, unless indicated otherwise in a credit line to the material. If material is not included in the article's Creative Commons licence and your intended use is not permitted by statutory regulation or exceeds the permitted use, you will need to obtain permission directly from the copyright holder. To view a copy of this licence, visit http://creativecommons.org/licenses/by/4.0/.

\section{References}

Animal and Plant Health Inspection Service (2012) The 2012 prioritized offshore pest list. https://www.aphis.usda.gov/plant_ health/plant_pest_info/pest_detection/downloads/farmbill/ PrioritizedOffshorePestList.pdf. Accessed 31 Aug 2019

Burgiel SW (2019) The incident command system: a framework for rapid response to biological invasion. Biol Invasions. https://doi.org/10.1007/s10530-019-02150-2

Burgos-Rodríguez J, Burgiel SW (2019) Federal legal authorities for the early detection of and rapid response to invasive species. Biol Invasions. https://doi.org/10.1007/s10530019-02148-w

Drucker HR, Brown CS, Stohlgren TJ (2008) Developing regional invasive species watch lists: Colorado as a case study. Invasive Plant Sci Manag 1:390-398. https://doi. org/10.1614/IPSM-07-055.1

Environmental Law Institute (2004) Making a list: prevention strategies for invasive plants in the Great Lakes states. https://www.eli.org/research-report/making-listprevention-strategies-invasive-plants-great-lakes-states. Accessed 10 Sept 2019

Executive Office of the President (2016) Executive Order 13751, 81 FR 88609-88614, 5 December 2016

Faulkner KT, Robertson MP, Rouget M, Wilson JR (2014) A simple, rapid methodology for developing invasive species watch lists. Biol Conserv 179:25-32

Frey M (2017) An invasive plant watch list for the National Capital Regional National Parks (USA). Nat Areas J 37:108-117

Lyal CHC, Miller SE (2019) Capacity of United States federal government and its partners to rapidly and accurately 
report the identity (taxonomy) of non-native organisms intercepted in early detection programs. Biol Invasions. https://doi.org/10.1007/s10530-019-02147-x

Meyers NM, Reaser JK, Hoff MH (2019) Instituting a national early detection and rapid response program: needs for building federal risk screening capacity. Biol Invasions. https://doi.org/10.1007/s10530-019-02144-0

Morisette JT, Reaser JK, Cook GL, Irvine KM, Roy HE (2019) Right place. Right time. Right tool: guidance for using target analysis to increase the likelihood of invasive species detection. Biol Invasions. https://doi.org/10.1007/s10530019-02145-z

National Invasive Species Council (NISC) (2016) 2016-2018 NISC Management Plan. NISC Secretariat, Washington, $\mathrm{DC}$
Reaser JK, Burgiel SW, Kirkey J, Brantley KA, Veatch SD, BurgosRodríguez J (2019a) The early detection of and rapid response (EDRR) to invasive species: a conceptual framework and federal capacities assessment. Biol Invasions. https://doi.org/ 10.1007/s10530-019-02156-w

Reaser JK, Simpson A, Guala GF, Morisette JT, Fuller P (2019b) Envisioning a national invasive species information framework. Biol Invasions. https://doi.org/10.1007/ s10530-019-02141-3

Publisher's Note Springer Nature remains neutral with regard to jurisdictional claims in published maps and institutional affiliations. 